\title{
Autômatos Celulares aplicados ao estudo de Dinâmica Populacional de Fauna Cavernícola
}

\author{
Emanuelle A. Paixão* $\quad$ Rodrigo L. Ferreira \\ Depto de Biologia, UFLA, \\ 37200-000, Lavras, MG \\ E-mail: earantes@posgrad.ufla.br, drops@dbi.ufla.br, \\ Crysttian A. Paixão \\ Fundação Getulio Vargas - Escola de Matemática Aplicada \\ 22250-900, Praia de Botafogo, Botafogo, Rio de Janeiro, RJ \\ E-mail: crysttian.paixao@fgv.br
}

\section{RESUMO}

Autômatos celulares são uma das formas de modelagem aplicada para estudo de diversos fenômenos naturais, dentre eles destacam-se as dinâmicas populacionais [3]. Ainda existe pouco conhecimento sobre as características populacionais de espécies que habitam sistemas cavernícolas [1] [2] [4]. Portanto, autômatos celulares podem representar uma metodologia útil para um melhor entendimento sobre essas espécies e suas dinâmicas, por permitirem que as características individuais sejam utilizadas para estudar o comportamento do indivíduo e da população a qual pertence. Dessa maneira, pode-se obter maiores informações sobre o sistema natural e seu funcionamento ecológico. Os dados analisados correspondem à distruibuição espacial e temporal de dez espécies encontradas em uma caverna em sistema ferruginoso. Essas espécies estabelecem interações ecológicas entre si, destacando-se a competição e interação predador-presa. As amostras foram coletadas a cada três meses, durante dois anos, com levantamento detalhado da fauna existente na cavidade. O objetivo deste trabalho é representar os indivíduos de cada espécie no formato de autômato celular, avaliando a evolução do sistema e sua dinâmica por meio de parâmetros modelados como: abundância populacional, preferência alimentar, preferência de região, tamanho do passo de deslocamento e tempo de evolução. A abundância populacional corresponde ao tamanho da população de cada espécia estudada. Já a preferência alimentar representa a interação predador-presa, indicando a presa de preferência do predador. A preferência de região modela a região dentro da caverna na qual cada animal prefere permanecer, sendo esse parâmetro obtido por meio da análise espacial dos dados das amostragens. O tamanho do passo corresponde ao deslocamento do animal seguindo o movimento browniano em duas dimensões. Já o tempo de evolução corresponde ao tempo de evolução do sistema, sendo considerado em um primeiro momento o tempo correspondente ao desenvolvimento do experimento e das amostragens. Os dados reais permitiram a verificação dos resultados gerados pelos autômatos e também o ajuste adequado dos parâmetros utilizados. Como resultado preliminar das simulações, destaca-se a difusão dos animais pela cavidade, considerando a relação predador-presa, de forma semelhante ao caso real. A interação entre presas e predadores foi verificada, sendo que áreas com grandes concentrações de presas funcionaram como atratoras para os respectivos predadores. Também foi possível identificar o efeito da competição entre predadores que possuíam presas em comum. A modelagem empregada permitiu a avaliação do espalhamento desses animais no interior da caverna, contribuindo para um melhor entendimento das dinâmicas populacionais dessas espécies. Tal fato auxilia na proposta de estratégias de manejo mais efetivas para a preservação de espécies cavernícolas e do sistema ecólogico como um todo. O modelo ainda está em desenvolvi-

*bolsista de Mestrado CAPES 
mento e espera-se que um refinamento nos parâmetros possam ser obtidos a partir do estudo dos dados de distribuição espacial com o uso de técnicas de Estatística Espacial. Esses estudos indicarão padrões que poderão ser comparados com as simulações, permitindo uma melhor avaliação do modelo proposto.

\section{Referências}

[1] A.S. Auler; L.B. Piló, Introdução às cavernas em minério de ferro e canga. O Carste, 17 (2005) 70-72.

[2] R.L. Ferreira, A vida subterrânea nos campos ferruginosos. O Carste, 17 (2005) 106-115.

[3] K. Rohde, Cellular automata and ecology. Oikos, 110 (2005) 203-20770-72.

[4] M.S. Silva; R.P. Martins; R.L. Ferreira, Cave lithology determining the structure of the invertebrate communities in the Brazilian Atlantic Rain Forest. Biodiversity and Conservation, 20 (2011) 17131729. 